\title{
Effect of Ubiquinol supplementation on ovulation induction in Clomiphene Citrate resistance
}

\author{
Islam Mohamed Magdi Ammar (iD and Ahmed Mahmoud Abdou
}

\begin{abstract}
Background: Clomiphene Citrate is considered the gold-standard for induction of ovulation and has been used for several years to treat PCOS related infertility. Unfortunately, 15-40\% of women with PCOS are resistant to Clomiphene Citrate. The study aimed to evaluate potential benefits of adding the active form of Coenzyme Q10 (Ubiquinol) to Clomiphene Citrate compared with Human Menopausal Gonadotropins (hMG) in Clomiphene Citrate resistant PCOS patients. 148 PCOS Patients with Clomiphene Citrate resistance were randomized into two groups (A and B). In group A, controlled ovarian stimulation was done by Clomiphene Citrate $150 \mathrm{mg}$ daily (from 2nd till 6th day of cycle) together with Ubiquinol starting from 2 nd day till day of hCG triggering in a dose of $100 \mathrm{mg}$ orally once daily. In group B, hMG was given from 2 nd day of the cycle in a dose ranging from 75 to $225 \mathrm{IU}$. Serial transvaginal ultrasonography was done starting on cycle day 8 and continued till size of leading follicle reaches 18 $\mathrm{mm}$ or more then ovulation triggering was done. Thereafter, patients were advised for a timed intercourse (TI) after 36 hours. A blood sample was withdrawn seven days after hCG triggering, for measurement of serum progesterone. If the Patient presented with a missed period for one week, a serum sample was sent for $\beta$-hCG.

Results: There were no statistically significant differences $(P>0.05)$ between studied groups regarding; number of cases reaching mature follicular size, number of stimulated cycles, endometrial thickness on the day of hCG triggering, mid-luteal serum progesterone, positive serum pregnancy test and clinical pregnancy rate.

Conclusions: Addition of Ubiquinol to Clomiphene Citrate improved ovarian responsiveness in Clomiphene Citrate resistant patients with results comparable to conventional hMG stimulation protocol.
\end{abstract}

Keywords: Clomiphene Citrate resistance, Ubiquinol, Coenzyme Q10, PCOS

\section{Background}

Seven to eight percent of women in reproductive age have polycystic ovary syndrome (PCOS) which is characterized by hyperandrogenemia and chronic anovulation [1]. Proper management of PCOS is based on accurate diagnosis. Rotterdam criteria have been widely used for diagnosis of PCOS, it requires two of three features; ultrasound picture of polycystic ovary, ovulatory disorders and/or clinical/biochemical signs of hyperandrogenism [2].

\footnotetext{
* Correspondence: islamammar146@gmail.com

Department of Obstetrics and Gynecology, Faculty of Medicine, Zagazig University, Zagazig City, Sharkia, Egypt
}

\section{Springer Open}

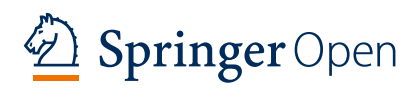

Clomiphene Citrate (CC) is cheap, effective and safe drug; thus, it is the first line for induction of ovulation $[3,4]$. About $15-40 \%$ of women with PCOS have Clomiphene Citrate resistance (CCR) which was defined as failure of ovulation after receiving $150 \mathrm{mg}$ Clomiphene Citrate per day [4]. Many factors have been incriminated in Clomiphene Citrate resistance including androgen excess, insulin resistance (IR), increased body mass index (BMI) [5] and hereditary predisposition [6].

Many dietary supplementations have a role in health promotion and had abundant attention in the last few years. Coenzyme Q10 (CoQ10) is a benzoquinone which is lipid-soluble and is being involved in the respiratory

(c) The Author(s). 2021 Open Access This article is licensed under a Creative Commons Attribution 4.0 International License, which permits use, sharing, adaptation, distribution and reproduction in any medium or format, as long as you give appropriate credit to the original author(s) and the source, provide a link to the Creative Commons licence, and indicate if changes were made. The images or other third party material in this article are included in the article's Creative Commons licence, unless indicated otherwise in a credit line to the material. If material is not included in the article's Creative Commons licence and your intended use is not permitted by statutory regulation or exceeds the permitted use, you will need to obtain permission directly from the copyright holder. To view a copy of this licence, visit http://creativecommons.org/licenses/by/4.0/. 
chain of mitochondria for ATP production [7]. CoQ10 is a good antioxidant because it has the ability to maintain continuous cycles of oxidation-reduction [8]. Many recent studies concluded that CoQ10 supplementation improves endocrine and metabolic functions of PCOS patients $[9,10]$. Also, it improves insulin resistance [11], causes reduction of blood pressure [12] and recovers endothelial functions [13].

The second-line therapy for induction of ovulation, in PCOS patients with Clomiphene Citrate resistance, is gonadotropins. Although, they have many disadvantages; being expensive, requiring meticulous follow up of patients during induction as there is high risk of ovarian hyperstimulation syndrome (OHSS) and multiple pregnancies $[3,14]$.

Aim of the study:

This study was conducted to evaluate the potential benefit of adding the active form of Coenzyme Q10 (Ubiquinol) to Clomiphene Citrate when compared with Human Menopausal Gonadotropins (hMG) in Clomiphene Citrate resistant PCOS patients, and eventually; the possibility of using Ubiquinol / Clomiphene Citrate combination as an alternative to the conventional hMG stimulation protocol.

\section{Methods}

The study was conducted in the department of Obstetrics and Gynaecology of the Saudi German Hospital, Madinah- Kingdom of Saudi Arabia, as a randomized clinical trial during the period from April 2019 to July 2020. The study protocol was approved by the local ethics committee. Before participating in the study, a written informed consent was obtained from all patients. The study included 148 patients with Clomiphene Citrate resistant PCOS who fulfilled the following inclusion criteria: age 18 to 35 years, Body mass index (BMI) between 18.5 and $34.9 \mathrm{~kg} / \mathrm{m} 2$, presenting with primary or secondary infertility. PCOS was diagnosed according to the Rotterdam ESHRE/ASRM Consensus workshop [3], with at least 2 of the following 3 criteria:

A- Oligo- and/or anovulation; manifested by oligomenorrhea or amenorrhea. Oligomenorrhea was defined as cycle interval of more than 35 days but less than six months. Amenorrhea was defined as absence of menstruation for six months or more.

B- Hyperandrogenism; biochemical and/or clinical in the form of acne or hirsutism defined as a score of 8 or higher using the modified Ferriman-Gallwey scoring system [15] when abnormal hair distribution was assessed in nine body areas and given a score of 0 to 4 .

C - Polycystic ovarian morphology detected by transvaginal ultrasound with the presence of 12 or more follicles measuring 2-9 $\mathrm{mm}$ in diameter in one or both ovaries, and/or increased ovarian volume $>10 \mathrm{~mL}$.
With exclusion of other etiologies that may also lead to oligoovulation and/or androgen excess such as androgen-secreting tumors, congenital adrenal hyperplasia, hyperprolactinemia or Cushing's syndrome.

Patients with anovulation who had clinical or laboratory evidence for hyperandrogenaemia were primarily assessed for the cause before establishing the diagnosis of PCOS and indeed before exposure to clomiphene citrate as a first line for ovulation induction. In this study, we enrolled only PCOS patients with clomiphene citrate resistance. Patients with hyperandrogenaemia due to other causes such as, androgen secreting tumours diagnosed when the level of testosterone is higher than $2 \mathrm{ng} /$ $\mathrm{mL}$, and congenital adrenal hyperplasia diagnosed by high level of $17-\mathrm{OH}$ progesterone, were excluded.

Clomiphene Citrate resistance was defined as failure of ovulation after administration of Clomiphene Citrate in a dose of $150 \mathrm{mg}$ for 5 days per cycle, for two or three cycles [4]. All Patients had patent both fallopian tubes and normal uterine cavity as evidenced by hysterosalpingography (HSG) and their partners had normal semen parameters as defined by the modified WHO 2010 criteria [16].

Exclusion criteria were: Morbidly obese patients with BMI $\geq 35 \mathrm{Kg} / 2 \mathrm{~m}$, abnormal husband semen analysis, abnormal HSG or laparoscopic evidence of pelvic adhesions. Patients receiving statin drugs for cholesterol, beta-blockers for high blood pressure, or tricyclic antidepressants, were also excluded as these drugs can lower the levels of ubiquinol in the body.

\section{Initial Assessment}

All patients were initially assessed at the booking visit, with detailed history taking, including personal, medical, surgical, obstetric and menstrual history. The body mass index (BMI) was calculated. Basal hormonal profile; serum follicle stimulating hormone (FSH) and luteinizing hormone (LH), were measured using Enzyme Linked Immunosorbent Assay (ELISA).

\section{Ovarian stimulation and folliculometry}

Patients were divided randomly into two groups (A and B), who underwent controlled ovarian stimulation and timed intercourse, using random table computer software (Open Epi version 3.21).

Basal transvaginal ultrasonography (TVS) was done on day 2 of the cycle before commencing ovarian stimulation. For patients presenting with amenorrhea or oligomenorrhea, dydrogesterone $10 \mathrm{mg}$ (Duphaston'; Abbott Biologicals B.V.) was prescribed (3 times daily for 10 days) to achieve withdrawal bleeding before starting induction of ovulation.

In group $\mathrm{A}$, controlled ovarian stimulation (COS) was done by Clomiphene Citrate (Fertab $50 \mathrm{mg}$ tablets, 
Zynova. SITCO Pharma.) as $150 \mathrm{mg}$ (3 tablets) daily for 5 days (from 2nd day till 6th day of the cycle) together with Ubiquinol (active form of Coenzyme Q10) starting from 2nd day till the day of human Chorionic Gonadotropin (hCG) triggering in a dose of $100 \mathrm{mg}$ capsules orally once daily, immediately after meal (Nutraquinol'; Jamjoom Pharma Nutraceuticals). In group B, Human Menopausal Gonadotropins (hMG) (Merional ${ }^{\circ} 75$ I.U. vials, IBSA.) IM was given from 2 nd day of the cycle in a dose ranging from 75 to $225 \mathrm{IU}$ according to the patient's response. Patients were instructed not to take any non-study drugs during the whole study period. All patients did not receive any drug for induction of ovulation 3 months prior to participation in the study.

Patients were counselled regarding the possible side effects of Clomiphene Citrate such as: reversible enlargement of the ovaries, multiple pregnancy, ovarian hyperstimulation syndrome, blurred vision, light sensitivity, headache, hot flushes, mild abdominal pain and vaginal bleeding [17] as well as the possible side effects of Human Menopausal Gonadotropins such as: pain at the site of injection, abdominal discomfort and pelvic pain, breast discomfort, ovarian hyperstimulation syndrome, multiple pregnancy, weight gain, headache, mood changes, nausea, abnormal uterine bleeding, dizziness, ovarian cysts, adnexal torsion or ruptured ovarian cyst and ectopic pregnancy [18].

Serial transvaginal ultrasonography was done for assessment of follicular growth (number and diameter of follicles) and endometrial thickness (measured on sagittal view of the uterus by including the whole endometrium at the point of its maximum thickness), starting on cycle day 8, using vaginal $4.5 \mathrm{MHz}$ endocavity transducer (Esaote Mylab 50 Xvision Ultrasound, Italy), and was continued with an interval of 1-3 days till the size of the leading follicle reaches $18 \mathrm{~mm}$ or more in mean follicular diameter. Then ovulation triggering was done by an intramuscular single dose of human Chorionic Gonadotropin (Epifasi ${ }^{\circ}$ 5000 IU vials, EIPICO, Egypt.) 2 vials (10,000 IU). Thereafter, patients were advised for a timed intercourse (TI) 36 hours after ovulation triggering.

All measurements were obtained by a blinded single operator. All data were digitally stored and were not analyzed till the end of the study.

Thereafter, patients were asked to come for follow up, 7 days after hCG triggering, where a blood sample (2 $\mathrm{mL}$ ) was withdrawn for measurement of serum progesterone $(\mathrm{ng} / \mathrm{ml})$. Collected samples were centrifuged and then stored at $2-8{ }^{\circ} \mathrm{C}$ until enzyme immunoassay was done. If the Patient presented with a missed period for a week, a serum sample was sent for $\beta$-hCG using immunoassay.

Patients with positive serum pregnancy test, defined as $\beta$-hCG concentration $>10 \mathrm{mU} / \mathrm{ml}$, were examined by abdominal ultrasonography 6 weeks after the first day of their last menstrual period with $3.5 \mathrm{MHz}$ sector transducer (Esaote Mylab 50 Xvision Ultrasound, Italy) to detect an intrauterine gestational sac (Clinical pregnancy) [19]. Patients who failed to get pregnant were requested for follow up for 2 more consecutive cycles with the same protocol.

The primary outcomes measured were; number of cases achieving follicular growth to the size of mature follicle $\geq 18 \mathrm{~mm}$ (1-3 follicles) during the three cycles of stimulation, number of stimulated cycles (till pregnancy occurs or completing the 3 cycles of the study, whichever is earlier), the endometrial thickness on the day of triggering, and the luteal function as assessed by midluteal serum progesterone measurements.

The secondary outcomes were; number of cases with positive serum pregnancy test and the clinical pregnancy rate among the two groups during the three cycles of treatment.

2.3. Sample size calculation: was done using a computer software G Power ${ }^{\bullet}$ version 3.1.5 (Franz Faul, Universität Kiel, Germany).

\section{Results}

211 patients with Clomiphene Citrate resistant PCOS, presenting with primary or secondary infertility, visited the outpatient clinic during the study period. Assessment for eligibility was done and 175 patients were fitting the inclusion criteria. The protocol of study, the intervention involved, possible short- and long-term side effects of interventions were fully discussed with the patients. 161 patients were willing to participate and signed an informed consent for participation. Simple randomization of those patients was done where 81 cases were allocated in group A (ovarian stimulation by Clomiphene Citrate $150 \mathrm{mg}$ daily for 5 days, from 2 nd to 6th day of the cycle, together with Ubiquinol starting from 2nd day till the day of human Chorionic Gonadotropin (hCG) triggering in a dose of $100 \mathrm{mg}$ capsules orally once daily), and 80 cases in group B (ovarian stimulation by Human Menopausal Gonadotropins (hMG) 75 to 225 IU IM from 2nd day of the cycle).

Patients who were dropped from follow up were excluded from the study statistics and results ( 6 and 7 patients from group A and B respectively). So, eventually, analysis was done for 148 patients (75 and 73 patients from group A and B respectively). The flowchart of the participants is shown in (Fig. 1).

Regarding the demographic and clinical parameters (i.e. age, BMI, type of infertility and duration of infertility), there were no statistically significant differences $(\mathrm{P}>0.05)$ between the 2 studied groups as shown in (Table 1). 


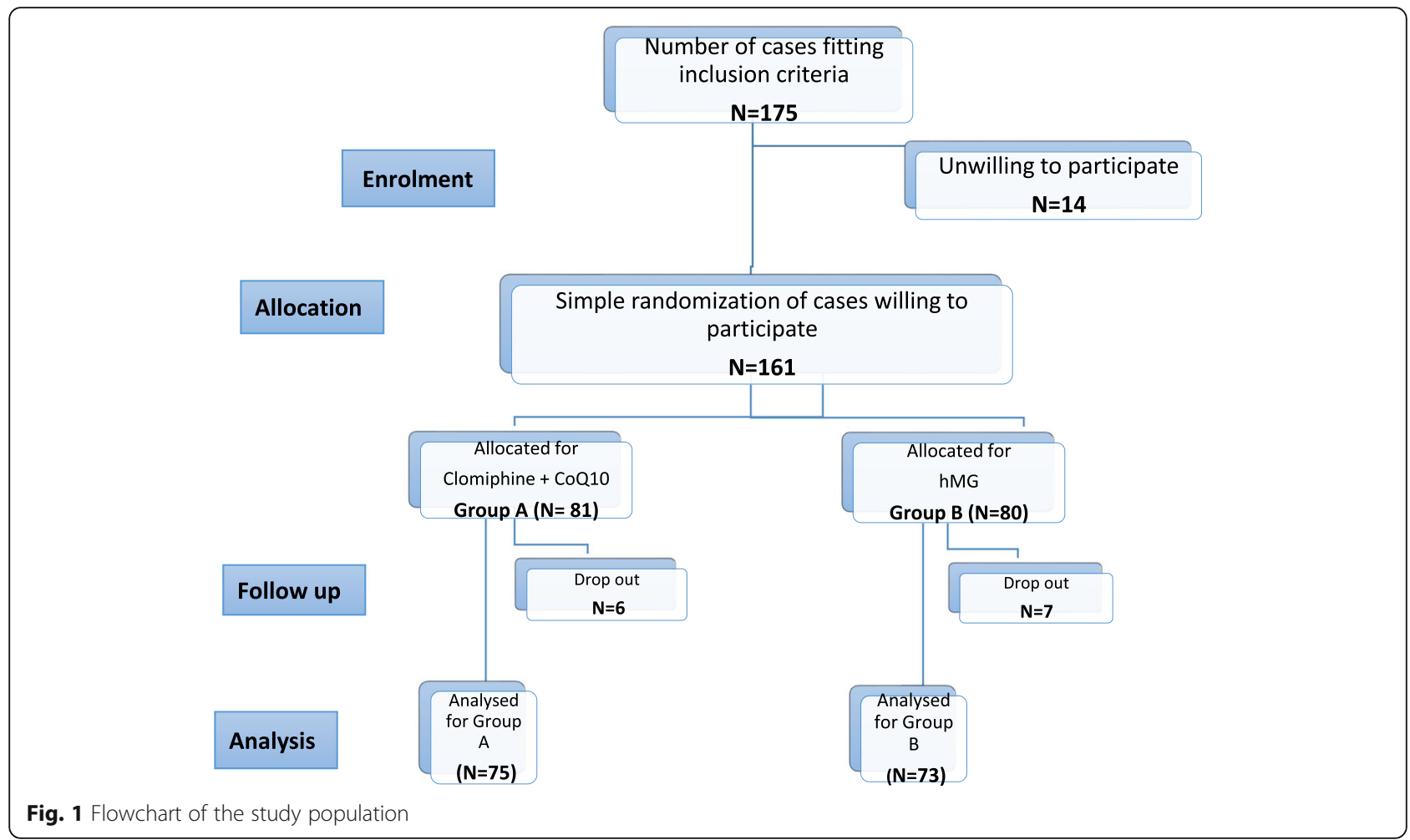

Table 1 Demographic and clinical data of the study population

\begin{tabular}{|c|c|c|c|c|}
\hline & $\begin{array}{l}\text { All patients } \\
(\mathrm{N}=148)\end{array}$ & $\begin{array}{l}\text { Group A } \\
(\mathrm{N}=75)\end{array}$ & $\begin{array}{l}\text { Group B } \\
(\mathrm{N}=73)\end{array}$ & $p$-value \\
\hline \multicolumn{5}{|l|}{ Age (years) } \\
\hline Mean \pm SD & $26.59 \pm 7.00$ & $26.68 \pm 6.99$ & $26.51 \pm 7.02$ & \\
\hline$\leq 20$ years & $23(15.6 \%)$ & $12(16.0 \%)$ & $11(15.1 \%)$ & 0.93 \\
\hline $21-29$ years & $89(60.1 \%)$ & $44(58.7 \%)$ & $45(61.6 \%)$ & \\
\hline$\geq 30$ years & $36(24.3 \%)$ & 19 (25.3\%) & $17(23.3 \%)$ & 0.92 \\
\hline \multicolumn{5}{|l|}{ BMI $\left(\mathrm{kg} / \mathrm{m}^{2}\right)$} \\
\hline Mean \pm SD & $27.48 \pm 4.80$ & $27.34 \pm 4.89$ & $27.62 \pm 4.71$ & \\
\hline Average & 34 (23.0\%) & $18(24.0 \%)$ & $16(22.0 \%)$ & 0.74 \\
\hline Overweight & $83(56.1 \%)$ & $41(54.7 \%)$ & $42(57.5 \%)$ & \\
\hline Obese & $31(20.9 \%)$ & $16(21.3 \%)$ & $15(20.5 \%)$ & 0.93 \\
\hline \multicolumn{5}{|l|}{ Type of infertility } \\
\hline Primary & 87 (58.8\%) & $44(58.7 \%)$ & $43(58.9 \%)$ & \\
\hline Secondary & $61(41.2 \%)$ & $31(41.3 \%)$ & $30(41.1 \%)$ & 0.97 \\
\hline \multicolumn{5}{|c|}{ Duration of infertility (years) } \\
\hline Mean \pm SD & $2.53 \pm 1.48$ & $2.47 \pm 1.39$ & $2.59 \pm 1.57$ & 0.63 \\
\hline \multicolumn{5}{|l|}{ FSH (IU/L) } \\
\hline Mean \pm SD & $5.47 \pm 2.25$ & $5.67 \pm 2.36$ & $5.28 \pm 2.15$ & 0.31 \\
\hline \multicolumn{5}{|l|}{ LH (IU/L) } \\
\hline Mean \pm SD & $5.24 \pm 1.69$ & $5.43 \pm 1.74$ & $5.05 \pm 1.65$ & 0.17 \\
\hline Testosterone (ng/mL) & $0.64 \pm 0.18$ & $0.62 \pm 0.15$ & $0.66 \pm 0.17$ & 0.91 \\
\hline
\end{tabular}


As regard the basal hormonal profile (serum FSH, LH and testosterone), there was no statistically significant difference $(\mathrm{P}>0.05)$ between the 2 studied groups. The mean value for basal serum FSH levels in group A was $5.67 \pm 2.36 \mathrm{IU} / \mathrm{L}$ compared to $5.28 \pm 2.15 \mathrm{IU} / \mathrm{L}$ in group B. The mean value for basal serum LH levels for group A was $5.43 \pm 1.74 \mathrm{IU} / \mathrm{L}$ compared to $5.05 \pm 1.65 \mathrm{IU} / \mathrm{L}$ for group B. The mean value for serum testosterone levels for group A was $0.62 \pm 0.15 \mathrm{ng} / \mathrm{mL}$ compared to $0.66 \pm 0.17 \mathrm{ng} / \mathrm{mL}$ for group B (Table 1).

There were no statistically significant differences $(\mathrm{P}>$ 0.05 ) between the 2 studied groups regarding the number of cases reaching mature follicular size during the study period $(60.0 \%$ compared to $64.4 \%$ in the first cycle, $59.2 \%$ compared to $63.2 \%$ in the second cycle, and $62.3 \%$ compared to $66.1 \%$ in the third cycle) as shown in (Table 2 \& Fig. 2). Regarding the number of mature follicles ( $\geq 18 \mathrm{~mm}$ in diameter on the day of triggering) and the diameter of dominant follicles, there were no statistically significant differences between the 2 groups ( $\mathrm{P}>$ 0.05 ) as shown in Table 2.

As regard the number of stimulated cycles during the study period, there were no statistically significant differences $(P>0.05)$ between the 2 studied groups $(75 \mathrm{com}-$ pared to 73 in the first cycle, 71 compared to 68 in the second cycle, and 61 compared to 59 in the third cycle) (Table 2 \& Fig. 3).

Regarding the endometrial thickness on the day of hCG triggering, there was no statistically significant difference $(\mathrm{P}=0.64)$ between both groups $(8.98 \pm 2.97 \mathrm{~mm}$ in group A compared to $9.21 \pm 2.58 \mathrm{~mm}$ in group B) as shown in (Table 2).

As regard the mean values of mid-luteal serum progesterone, there was no statistically significant difference $(\mathrm{P}=0.88)$ between both groups $(10.73 \pm 4.42 \mathrm{ng} / \mathrm{mL}$ in group A compared to $10.82 \pm 4.57 \mathrm{ng} / \mathrm{mL}$ in group B) as shown in (Table 2).

Regarding the number of pregnancies diagnosed by positive serum pregnancy test, there was no statistically significant difference $(\mathrm{P}=0.61)$ between both groups, with 15 pregnancies achieved in group A (20.0\%)) compared to 17 pregnancies $(23.3 \%)$ in group B (Table $3 \&$ Fig. 4).

There was no statistically significant difference between both groups as regard the clinical pregnancy rate $(\mathrm{P}=0.77)$ with 14 pregnancies $(18.7 \%)$ achieved in group A compared to 15 pregnancies $(20.5 \%)$ in group B (Table 3 \& Fig. 5). As regard the number of cases of multiple pregnancy and the number of miscarriages, there were no statistically significant differences between the 2 groups ( $\mathrm{P}=0.38$ and 0.69 respectively) as shown in Table 3.

\section{Discussion}

Ovarian function could be improved by CoQ10 supplementation through several mechanisms; it has antioxidant and anti-apoptotic activities, it also causes stabilization of cell membrane and improves mitochondrial ATP production [20]. Mitochondrial production of energy was significantly improved by CoQ10 supplementation [21]. Normal maturation, fertilization of oocyte, development of embryos and synthesis of steroid hormones could not be achieved except with good mitochondrial production of energy [22]. Oocyte mitochondrial dysfunction in the form of reduced mitochondrial adenosine triphosphate (ATP) production due to diminished oxidative phosphorylation will lead to reduced reproductive functions; decreased quality of oocyte, ovarian reserve, fertilization, and development of embryos [23, 24].

Table 2 The primary outcomes

\begin{tabular}{|c|c|c|c|c|}
\hline Outcomes & $\begin{array}{l}\text { All patients } \\
(\mathrm{N}=148)\end{array}$ & $\begin{array}{l}\text { Group A } \\
(\mathrm{N}=75)\end{array}$ & $\begin{array}{l}\text { Group B } \\
(\mathrm{N}=73)\end{array}$ & p-value \\
\hline \multicolumn{5}{|l|}{ Cases reaching mature follicular size during the study period: } \\
\hline Cycle 1 & $92(62.2 \%)$ & $45(60.0 \%)$ & $47(64.4 \%)$ & 0.712 \\
\hline Cycle 2 & $85(61.2 \%)$ & $42(59.2 \%)$ & $43(63.2 \%)$ & 0.711 \\
\hline Cycle 3 & $77(64.2 \%)$ & $38(62.3 \%)$ & $39(66.1 \%)$ & 0.722 \\
\hline \multicolumn{5}{|l|}{ Number of stimulated cycles during the study period * } \\
\hline Cycle 1 & 148 & $75(100 \%)$ & $73(100 \%)$ & 1.00 \\
\hline Cycle 2 & 139 & $71(94.7 \%)$ & $68(93.2 \%)$ & 0.91 \\
\hline Cycle 3 & 120 & $61(81.3 \%)$ & $59(80.8 \%)$ & 0.96 \\
\hline Number of follicles $\geq 18 \mathrm{~mm}$ in diameter on the day of hCG triggering & $1.19 \pm 0.38$ & $1.14 \pm 0.34$ & $1.24 \pm 0.37$ & 0.51 \\
\hline Diameter of dominant follicle (mm) & $20.4 \pm 6.3$ & $20.3 \pm 6.1$ & $20.6 \pm 5.9$ & 0.98 \\
\hline Endometrial thickness $(\mathrm{mm})$ on the day of $\mathrm{hCG}$ triggering & $9.09 \pm 2.77$ & $8.98 \pm 2.97$ & $9.21 \pm 2.58$ & 0.64 \\
\hline Mid-luteal Serum progesterone $(\mathrm{ng} / \mathrm{mL})$ & $10.77 \pm 4.49$ & $10.73 \pm 4.42$ & $10.82 \pm 4.57$ & 0.88 \\
\hline
\end{tabular}

*Number of stimulated cycles till pregnancy occurs or completing the 3 cycles of the study (whichever is earlier). 


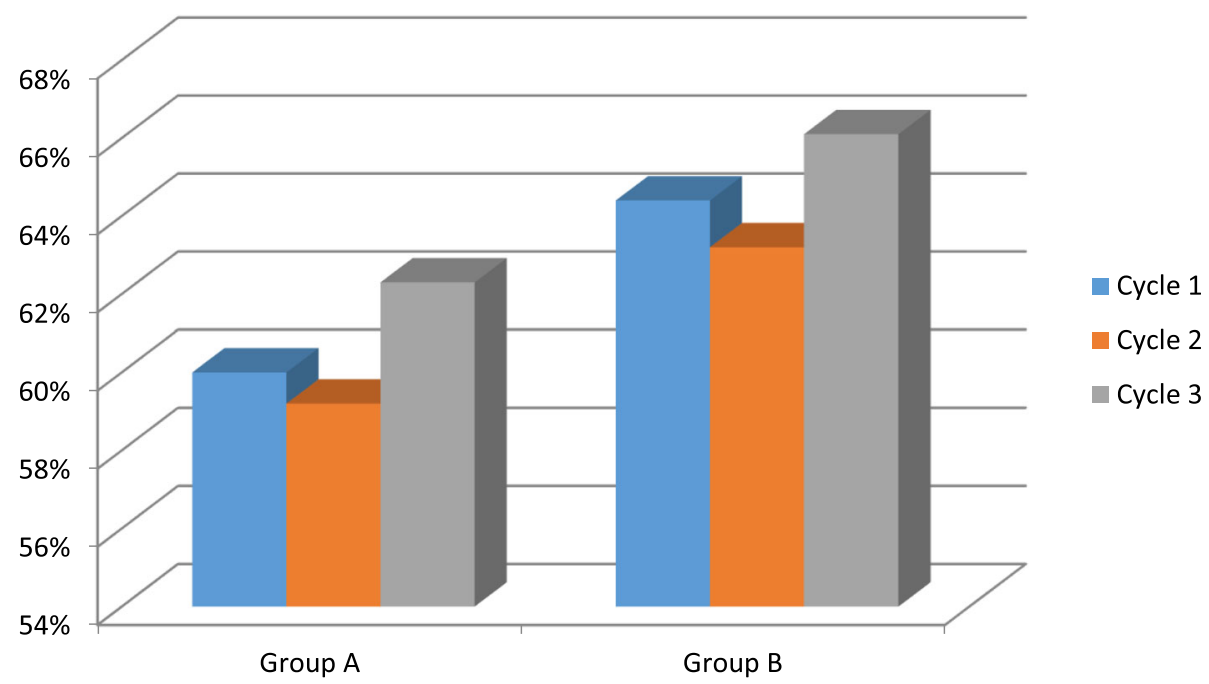

Fig. 2 Cases reaching mature follicular size during the study period

In this study, there were no statistically significant differences $(P>0.05)$ between the 2 studied groups (Clomiphene Citrate plus CoQ10 versus hMG) regarding the number of cases reaching mature follicular size during the study period $(60.0 \%$ compared to $64.4 \%$ in the first cycle, $59.2 \%$ compared to $63.2 \%$ in the second cycle, and $62.3 \%$ compared to $66.1 \%$ in the third cycle). As regard the mean values of mid-luteal serum progesterone, there was no statistically significant difference $(\mathrm{P}=0.88)$ between both groups $(10.73 \pm 4.42 \mathrm{ng} / \mathrm{mL}$ in group $A$ compared to $10.82 \pm 4.57 \mathrm{ng} / \mathrm{mL}$ in group B).

Regarding the number of pregnancies diagnosed by positive serum pregnancy test, there was no statistically significant difference $(\mathrm{P}=0.61)$ between both groups, with 15 pregnancies achieved in group A (20.0\%)) compared to 17 pregnancies $(23.3 \%)$ in group B. Also, there was no statistically significant difference between both groups as regard the clinical pregnancy rate $(\mathrm{P}=0.77)$ with 14 pregnancies (18.7\%) achieved in group A compared to 15 pregnancies (20.5\%) in group B.

Several previous studies demonstrated the role of supplementation of CoQ10 in women with PCOS.

El Refaeey et al. studied the effect of CoQ10 supplementation in Clomiphene Citrate resistant PCOS patients and found that ovulation happened in $65.6 \%$ of patients $(54 / 82$ cycles) in CoQ10 group compared to $15.5 \%$ in control group. Clinical pregnancy rate in CoQ10 group was significantly higher as compared to control group (37.3\% and 6\%, respectively) [20].

Also, Lakshmi et al. studied the effect of adding CoQ10 to Clomiphene Citrate in ovulation induction in PCOS patients and found significantly higher number of

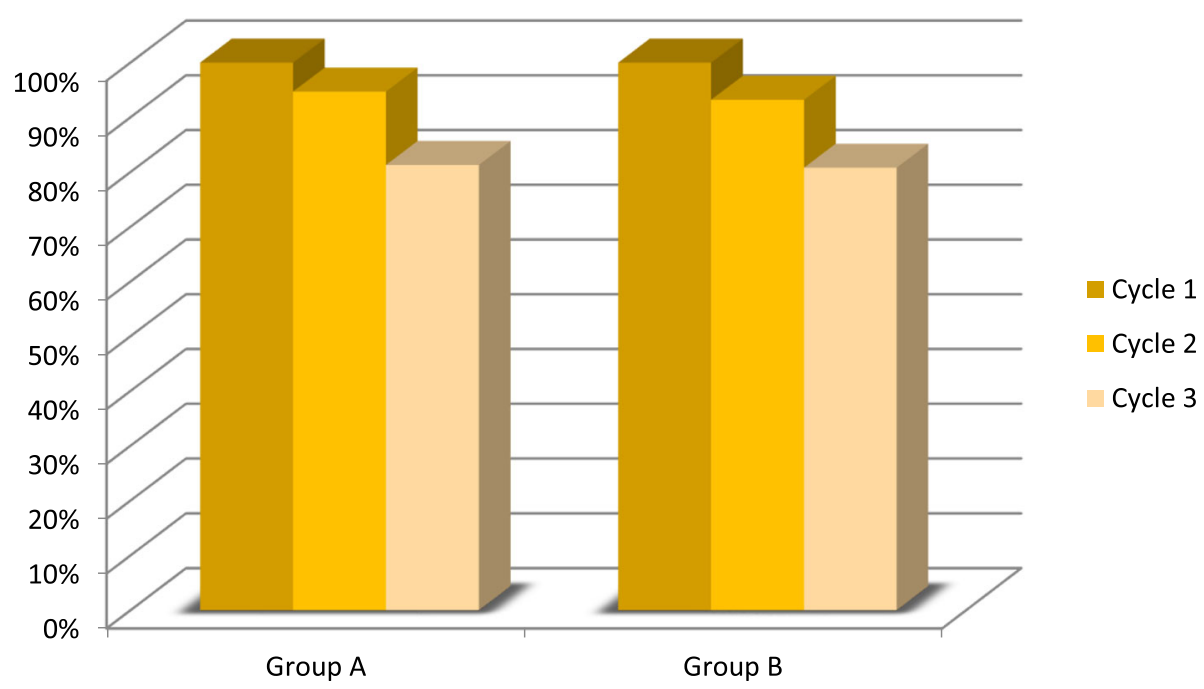

Fig. 3 Number of stimulated cycles during the study period 
Table 3 The secondary outcomes

\begin{tabular}{|c|c|c|c|c|}
\hline Pregnancy rate & $\begin{array}{l}\text { All patients } \\
(\mathrm{N}=148)\end{array}$ & $\begin{array}{l}\text { Group A } \\
(\mathrm{N}=75)\end{array}$ & $\begin{array}{l}\text { Group B } \\
(\mathrm{N}=73)\end{array}$ & p-value \\
\hline Cases with positive serum pregnancy test & $32(21.6 \%)$ & $15(20.0 \%)$ & $17(23.3 \%)$ & 0.61 \\
\hline Clinical pregnancies & $29(19.6 \%)$ & $14(18.7 \%)$ & $15(20.5 \%)$ & 0.77 \\
\hline Multiple pregnancy & $6(4.0 \%)$ & $2(2.67 \%)$ & $4(5.48 \%)$ & 0.38 \\
\hline Miscarriages & $9(6.0 \%)$ & $4 / 75(5.33 \%)$ & $5 / 73(6.85 \%)$ & 0.69 \\
\hline
\end{tabular}

follicles $>14 \mathrm{~mm}$ and $>18 \mathrm{~mm}$ in CoQ10 group than control group. Also, they found significantly greater endometrial thickness, higher serum estradiol level and clinical pregnancy in CoQ10 group [25].

Yahya et al. studied the effect of supplementation of either CoQ10 or vitamin D3 for 2 months in Clomiphene Citrate resistant PCOS patients and found that ovulation occurred in 13/17 (76.5\%) and clinical pregnancy occurred in 3/17 (17.6\%) of patients in CoQ10 group. The overall treatment outcome of both groups in their study has shown that ovulation rate was improved significantly as compared to Clomiphene Citrate alone according to pre-treatment baseline data. Therefore, they concluded that combination of Clomiphene Citrate with either of them seems to be a promising, effective and safe in ovulation induction in Clomiphene Citrate resistant PCOS patients [26].

PEKCAN et al. studied the effect of coenzyme Q10 supplementation on the cumulative pregnancy rate in young infertile PCOS patients with Clomiphene Citrate failure or resistance undergoing ovulation induction and intrauterine insemination (IUI). 130 infertile patients were included in this prospective study and were divided into 2 groups. The study group received CoQ10 (Ubiquinone) $100 \mathrm{mg}$ twice daily for one month. The control group received no treatment. Thereafter, patients underwent ovulation induction (by sequential $\mathrm{CC}$ and gonadotropins) and IUI till pregnancy occurred or for 3 months. The authors concluded that short term supplementation of CoQ10 had no therapeutic benefit on the cumulative pregnancy rate. The authors also stated that they had some limitations like the short duration of treatment (only one month of Ubiquinone) and the short follow up time [27].

As far we know, this is the first study to evaluate the beneficial effect of combining the active form of Coenzyme Q10 (Ubiquinol) and Clomiphene Citrate when compared with Human Menopausal Gonadotropins (hMG) in PCOS patients with Clomiphene Citrate resistance.

The achieved clinical pregnancy rate with Ubiquinol / Clomiphene Citrate combination was comparable $(\mathrm{P}=$ 0.77) to that achieved in the Human Menopausal Gonadotropins (hMG) group (14 pregnancies in group A compared to 15 pregnancies in group B). Taking into consideration, the disadvantages of hMG stimulated cycles; the required close monitoring of follicular growth, the higher risk of multifetal gestations and ovarian hyperstimulation syndrome and notably the higher price which represents a significant economic burden on the lower economic standard patients who unfortunately had to postpone their treatment cycles because of such

\section{Cases with positive serum pregnancy test}

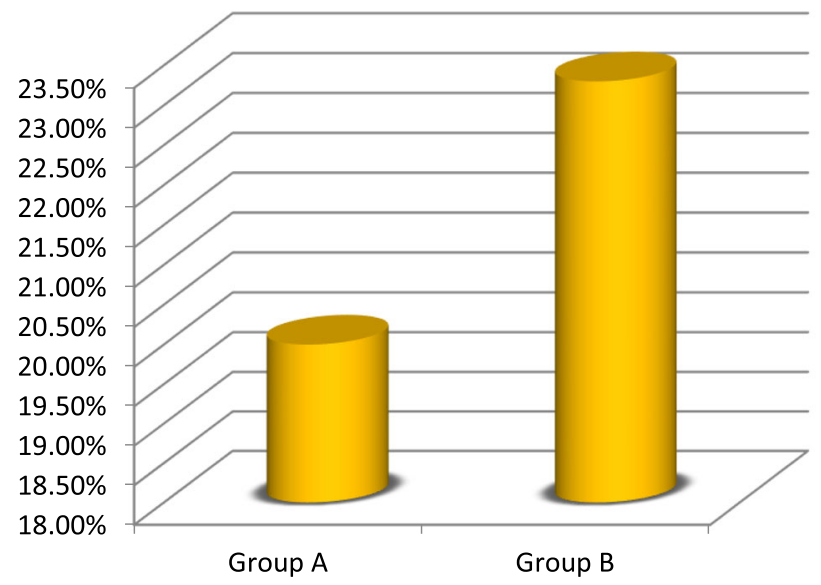

Cases with positive serum pregnancy test

Fig. 4 Cases with positive serum pregnancy test 


\section{Clinical pregnancies}

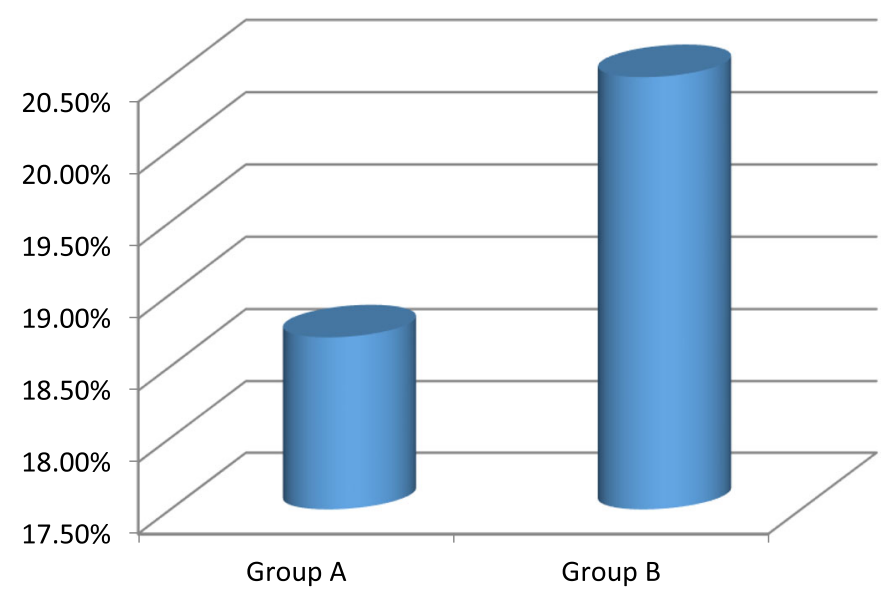

Clinical pregnancies

Fig. 5 Clinical pregnancy rate

financial cause [28], we can thereby assume that; Ubiquinol / Clomiphene Citrate combination can be a useful cheaper and safer alternative to the conventional hMG protocol in patients with Clomiphene Citrate resistance.

\section{Limitations of this study}

Limitations of this study were; the studied drugs (Clomiphene Citrate, Ubiquinol and Human Menopausal Gonadotropins) were not covered by medical insurance in Saudi Arabia, the need for frequent hospital visits for transvaginal folliculometry and withdrawal of blood samples for serum progesterone assay. Also, we did not follow up the outcome of the ongoing pregnancies.

\section{Conclusions}

The addition of the active form of Coenzyme Q10 (Ubiquinol) to Clomiphene Citrate improved the ovarian responsiveness in Clomiphene Citrate resistant patients in terms of follicular growth to the size of mature follicle, number of stimulated cycles, the endometrial thickness on the day of triggering, the luteal function and consecutively the pregnancy rate with results comparable to the conventional hMG stimulation protocol.

\section{Abbreviations}

ATP: Adenosine triphosphate; BMI: Body mass index; CC: Clomiphene Citrate; CCR: Clomiphene Citrate resistance; CoQ10: Coenzyme Q10; COS: Controlled ovarian stimulation; ELISA: Enzyme Linked Immunosorbent Assay; FSH: Follicle stimulating hormone; hCG: Human Chorionic Gonadotropin; hMG: Human Menopausal Gonadotropins; HSG: Hysterosalpingography; IR: Insulin resistance; IUI: Intrauterine insemination; LH: Luteinizing hormone; OHSS: Ovarian hyperstimulation syndrome; PCOS: Polycystic ovary syndrome; TVS: Transvaginal ultrasonography

\section{Acknowledgements}

The two authors would like to thank all the staff members of the departments of Obstetrics and Gynaecology and clinical pathology, of the Saudi German Hospital, Madinah as well as all included patients for their valuable participation to this work.

\section{Availability of data and material}

The data that support the findings of this study are available from the corresponding author, (Islam Mohamed Magdi Ammar), upon reasonable request.

Authors' contributions

IMMA: conception and design of study, acquisition of data, and manuscript revision. AMA: analysis of data, manuscript drafting, and manuscript revision. All authors have read and approved the manuscript.

Funding

Not applicable

\section{Declarations}

\section{Ethics approval and consent to participate}

The Human Research Ethics Committee of the Saudi German Hospital Madinah has approved the study prospectively (Protocol reference number: SGHMMAR2019-OBGYN) and full ethical approval has been granted. Trial registration: ClinicalTrials.gov Identifier: NCT04870502 (Retrospectively registered on 9/4/2021). Written informed consent was obtained from all patients before participating in the study.

\section{Consent for publication}

Not applicable

\section{Competing interests}

The authors declare that there are no actual or potential conflicts of interest with respect to research, authorship and/or publication of this article.

Received: 4 May 2021 Accepted: 28 July 2021

Published online: 09 August 2021

\section{References}

1. Azziz R, Woods KS, Reyna R, Key TJ, Knochenhauer ES, Yildiz BO (2004 Jun 1) The prevalence and features of the polycystic ovary syndrome in an unselected population. The Journal of Clinical Endocrinology \& Metabolism. 89(6):2745-2749. https://doi.org/10.1210/jc.2003-032046

2. Berger JJ, Bates GW Jr (2014) Optimal management of subfertility in polycystic ovary syndrome. International journal of women's health. 6:613

3. ESHRE TT, ASRM-Sponsored PCOS Consensus Workshop Group (2008 Mar 1) Consensus on infertility treatment related to polycystic ovary syndrome. Fertility and sterility. 89(3):505-522

4. Brown J, Farquhar C, Beck J, Boothroyd C, Hughes E (2009) Clomiphene and anti-oestrogens for ovulation induction in PCOS. Cochrane Database of Systematic Reviews. 4. https://doi.org/10.1002/14651858.CD002249.pub4 
5. Parsanezhad ME, Alborzi S, Zarei A, Dehbashi S, Omrani G (2001 Oct 1) Insulin resistance in clomiphene responders and non-responders with polycystic ovarian disease and therapeutic effects of metformin. International Journal of Gynecology \& Obstetrics. 75(1):43-50. https://doi. org/10.1016/S0020-7292(01)00470-2

6. Overbeek A, Kuijper EA, Hendriks ML, Blankenstein MA, Ketel IJ, Twisk JW, Hompes PG, Homburg R, Lambalk CB (2009) Clomiphene Citrate resistance in relation to follicle-stimulating hormone receptor Ser680Ser-polymorphism in polycystic ovary syndrome. Human reproduction. 24(8):2007-2013. https://doi.org/10.1093/humrep/dep114

7. Alcázar-Fabra M, Navas P, Brea-Calvo G (2016) Coenzyme Q biosynthesis and its role in the respiratory chain structure. Biochimica et Biophysica Acta (BBA)-Bioenergetics 1857(8):1073-1078

8. Bentinger M, Brismar K, Dallner G (2007 Jun 1) The antioxidant role of coenzyme Q. Mitochondrion. 7:S41-S50. https://doi.org/10.1016/j.mito.2007. 02.006

9. Rahmani E, Jamilian M, Samimi M, Zarezade Mehrizi M, Aghadavod E, Akbari E, Tamtaji OR, Asemi Z (2018 Mar 4) The effects of coenzyme Q10 supplementation on gene expression related to insulin, lipid and inflammation in patients with polycystic ovary syndrome. Gynecological Endocrinology. 34(3):217-222. https://doi.org/10.1080/09513590.2017.1381 680

10. Samimi M, Zarezade Mehrizi M, Foroozanfard F, Akbari H, Jamilian M, Ahmadi S, Asemi Z (2017 Apr) The effects of coenzyme Q10 supplementation on glucose metabolism and lipid profiles in women with polycystic ovary syndrome: a randomized, double-blind, placebo-controlled trial. Clinical endocrinology. 86(4):560-566. https://doi.org/10.1111/cen.13288

11. Stojanović M, Radenković M (2017 Feb 1) A meta-analysis of randomized and placebo-controlled clinical trials suggests that coenzyme Q10 at low dose improves glucose and HbA1c levels. Nutrition Research. 38:1-2. https://doi.org/10.1016/j.nutres.2016.12.001

12. Ho MJ, Li EC, Wright JM (2016) Blood pressure lowering efficacy of coenzyme Q10 for primary hypertension. Cochrane database of systematic reviews. 3

13. Yang YK, Wang LP, Chen L, Yao XP, Yang KQ, Gao LG, Zhou XL (2015 Oct 23) Coenzyme Q10 treatment of cardiovascular disorders of ageing including heart failure, hypertension and endothelial dysfunction. Clinica Chimica Acta. 450:83-89. https://doi.org/10.1016/j.cca.2015.08.002

14. Vause TD, Cheung AP, Sierra S, Claman P, Graham J, Guillemin JA, Lapensée L, Steward S, Wong BC (2010) Society of Obstetricians and Gynaecologists of Canada. Int J Gynaecol Obstet. 111(1):95-100. https://doi.org/10.1016/j. ijgo.2010.07.001

15. Willis SK, Mathew HM, Wise LA, Hatch EE, Wesselink AK, Rothman KJ, Mahalingaiah S (2020 Mar) Menstrual patterns and self-reported hirsutism as assessed via the modified Ferriman-Gallwey scale: A crosssectional study. European Journal of Obstetrics \& Gynecology and Reproductive Biology. 6

16. Cooper TG, Noonan E, Von Eckardstein S, Auger J, Baker HW, Behre HM, Haugen TB, Kruger T, Wang C, Mbizvo MT, Vogelsong KM (2010 Jan 1) World Health Organization reference values for human semen characteristics. Human reproduction update. 16(3):231-245. https://doi.org/1 0.1093/humupd/dmp048

17. Yilmaz S, Sezer NY, Gönenç IM, IIlhan SE, Yilmaz E (2018 Apr 1) Safety of clomiphene citrate: a literature review. Cytotechnology. 70(2):489-495. https://doi.org/10.1007/s10616-017-0169-1

18. Practice Committee of the American Society for Reproductive Medicine (2012 Apr 1) Multiple gestation associated with infertility therapy: an American Society for Reproductive Medicine Practice Committee opinion. Fertility and Sterility. 97(4):825-834

19. Zegers-Hochschild F, Adamson GD, Dyer S, Racowsky C, De Mouzon J, Sokol R, Rienzi L, Sunde A, Schmidt L, Cooke ID, Simpson JL (2017 Sep 1) The international glossary on infertility and fertility care, 2017. Human reproduction. 32(9):1786-1801. https://doi.org/10.1093/humrep/dex234

20. El Refaeey A, Selem A, Badawy A (2014 Jul 1) Combined coenzyme Q10 and Clomiphene Citrate for ovulation induction in clomiphene-citrate-resistant polycystic ovary syndrome. Reproductive biomedicine online. 29(1):119-124. https://doi.org/10.1016/j.rbmo.2014.03.011

21. Marriage BJ, Clandinin MT, Macdonald IM, Glerum DM (2004 Apr 1) Cofactor treatment improves ATP synthetic capacity in patients with oxidative phosphorylation disorders. Molecular genetics and metabolism. 81(4):263272. https://doi.org/10.1016/j.ymgme.2003.12.008
22. Bentov Y, Yavorska T, Esfandiari N, Jurisicova A, Casper RF (2011 Sep 1) The contribution of mitochondrial function to reproductive aging. Journal of assisted reproduction and genetics. 28(9):773-783. https://doi.org/10.1007/ s10815-011-9588-7

23. Fragouli E, Wells D. Mitochondrial DNA assessment to determine oocyte and embryo viability. InSeminars in reproductive medicine 2015 Nov (Vol. 33, No. 06, pp. 401-409). Thieme Medical Publishers.

24. Meldrum DR (2013 Jan 1) Aging gonads, glands, and gametes: immutable or partially reversible changes? Fertility and sterility. 99(1):1-4. https://doi. org/10.1016/j.fertnstert.2012.10.044

25. Lakshmi B, Bhavani K, Sudhakar M, Parveen H (2018) A study on quality of life and effect of coenzyme-Q10 in polycystic ovarian syndrome patients. International Journal of Advances in Pharmacy Medicine and Bioallied Sciences. 6(1):14-21

26. Yahya AA, Abdulridha MK, Al-Rubuyae BJ, Al-Atar HA (2019) The Effect of Vitamin D and Co-enzyme Q10 Replacement Therapy on Hormonal Profile and Ovulation Statusin Women with Clomiphene Citrate Resistant Polycystic Ovary Syndrome. Journal of Pharmaceutical Sciences and Research. 11(1): 208-215

27. PEKCAN MK, TOKMAK A, ÖZAKŞIT G (2019) Effect of Short Term Supplementation of Coenzyme Q10 on Cumulative Pregnancy Rates in Young Infertile Women with Polycystic Ovarian Syndrome. Journal of Clinical Obstetrics \& Gynecology. 29(2):62-67. https://doi.org/10.5336/jcog.2 019-66096

28. Ammar IM, Salem MA (2018) Effect of oral Tadalafil on endometrial thickness in patients receiving Clomiphene Citrate for ovulation induction. Middle East Fertility Society Journal. 23(2):121-125. https://doi.org/10.1016/j. mefs.2017.09.001

\section{Publisher's Note}

Springer Nature remains neutral with regard to jurisdictional claims in published maps and institutional affiliations.

\section{Submit your manuscript to a SpringerOpen ${ }^{\circ}$ journal and benefit from:}

- Convenient online submission

- Rigorous peer review

- Open access: articles freely available online

- High visibility within the field

- Retaining the copyright to your article

Submit your next manuscript at $>$ springeropen.com 